\title{
Editorial
}

C'est avec grand plaisir que ce numéro de Voix plurielles accueille deux beaux dossiers, l'un et l'autre fascinants : « Savoirs littéraires et arts narratifs autochtones », dirigé par Isabella Huberman, Joëlle Papillon et Isabelle St-Amand; et « Exil et migration. Réflexions autour d'expériences et de vécus littéraires », dirigé par Domenico Cambria. Je remercie les directrices et le directeur de leur travail assidu et amical afin de nous offrir d'excellentes contributions sur des sujets de la plus vive actualité.

S'ajoutent à ce dossier un article fort opportun sur la pédagogie queer, ainsi que, dans la rubrique « Création » des œuvres de l'artiste britannique Roger Harvey, qui nous emmène dans le sud de la France afin d'y goûter la langue et la culture occitanes, aujourd'hui en danger de disparition.

Et puis, très attendus, la publication de deux articles qui ont reçu le premier et le second Prix de la meilleure communication d'étudiant.es lors du colloque de 1'APFUCC en 2021, et le compte rendu de l'ouvrage qui a obtenu le Prix du meilleur livre, que l'APFUCC a décerné également en 2021. Ce numéro conclut sur trois comptes rendus de littérature franco-canadienne.

Nous sommes encore en temps de pandémie.

Je vous souhaite une bonne lecture.

\section{Catherine Parayre}

